Brit. F. vener. Dis. (1969), 45, 223.

\title{
RELATIONSHIPS BETWEEN THE SENSITIVITIES in vitro OF Neisseria gonorrhoeae TO SPIRAMYCIN, PENICILLIN, STREPTOMYCIN, TETRACYCLINE, AND ERYTHROMYCIN ${ }^{\star} \dagger$
}

\author{
BY
}

ALICE REYN AND MICHAEL WEIS BENTZON

From the Neisseria Department and Department of Biostatistics, Statens Seruminstitut, Copenhagen, Denmark

In a clinical trial of spiramycin, Schmidt, Niordson, Reyn, and Bentzon (1965) observed a positive correlation between the susceptibility of gonococcal strains in vitro to spiramycin and sodium penicillin $G$, and that the gonococcal strains from thirteen patients not cured by spiramycin were less sensitive to penicillin. Positive correlation could also be demonstrated between the inhibitory values of spiramycin and tetracycline for strains that were both resistant to streptomycin and less sensitive to penicillin. Reyn and Bentzon (1968) confirmed that a comparatively high degree of resistance to spiramycin in vitro was correlated with an increased resistance to penicillin. The correlation was most evident for strains that were resistant to streptomycin. Another peculiar feature observed was that of the fourteen strains with moderately decreased susceptibility to penicillin; seven were highly sensitive to spiramycin but at the same time completely resistant to streptomycin. Strains with moderately decreased susceptibility to penicillin were rarely found in that material, and it was suggested that they might represent a group with special genetic qualities. In contrast to the Danish results reported Durel, Roiron, and Nicod (1967) did not observe any correlation between the susceptibility to penicillin and spiramycin in a study of 302 gonococcal strains. In the present study, the material was supplemented by selected groups of strains with a view to further analysis of the relationships between the sensitivities of gonococcal strains to spiramycin and penicillin.

*Received for publication February 3, 1969.

tThis study was supported by grants from the World Health Organization.

\section{Material and Methods}

In addition to the 173 gonococcal strains examined in the preceding paper mentioned above, 338 strains isolated during the years 1960-1968 were examined with penicillin (penicillin @, Leo), streptomycin (dihydrostreptomycinum (B), Leo), tetracycline (tetracyclin (B), Lepetit), and spiramycin (rovamycin (B, May and Baker). The sensitivity to erythromycin $₫$ (Abbott) was examined for 93 of the 338 new strains. Care was taken in selecting the supplementary material to include strains with varying degrees of decreased sensitivity to penicillin simultaneous with sensitivity to streptomycin. The whole series comprised 411 gonococcal strains covering a 1,000-fold range of sensitivity to penicillin; 279 of these were sensitive and 132 resistant to streptomycin. Except in the examination with erythromycin, the plate-dilution method described by Reyn and co-workers was used (Reyn, Korner, and Bentzon, 1958; Reyn, Bentzon, and Ericsson, 1963). The results were given in $\mu \mathrm{g} . / \mathrm{ml}$. of 50 per cent. inhibitory concentrations $\left(\mathrm{IC}_{50}\right.$-values). Strains with $\mathrm{IC}_{50}$-values $\geqq 0.045 \mu \mathrm{g}$. sodium penicillin $\mathrm{G}$ per $\mathrm{ml}$. were considered as being "less sensitive".

The sensitivity to erythromycin was determined by a diffusion method using 20 hours' prediffusion (Thomsen, 1962).

Five strains artificially made more resistant to penicillin by subculture at increasing concentrations of penicillin were examined in a special experiment. These strains were already less sensitive to penicillin and tetracycline and were completely resistant to streptomycin. The $\mathrm{IC}_{50}$-values of the original strains and two samples of each strain with different levels of increased resistance to penicillin were determined with penicillin, spiramycin, and erythromycin.

\section{Results}

The $\mathrm{IC}_{50}$-values obtained with penicillin and spiramycin for each of the 411 strains were plotted against each other in a coordinate system. It was 
found that, for strains that were sensitive to both penicillin and streptomycin, the $\mathrm{IC}_{50}$-values of penicillin did not seem to be correlated with the $\mathrm{IC}_{50}$-values for spiramycin. For strains less sensitive to penicillin, a positive correlation was seen between the $\mathrm{IC}_{50}$-values of penicillin and spiramycin, but this correlation was stronger for strains resistant to streptomycin than for those sensitive to streptomycin.

The correlation observed between the inhibitory values of penicillin, spiramycin, and streptomycin might depend upon the relationship to tetracycline, since the $\mathrm{IC}_{50}$-values of tetracycline have previously been shown to be correlated with the values of both penicillin and streptomycin (Reyn, 1961; Schmidt and Larsen, 1962; Reyn, 1963). A statistical analysis of the $\mathrm{IC}_{50}$-values obtained for the 411 gonococcal strains confirmed that, at given IC $_{50}$-values of penicillin, the $\mathrm{IC}_{50}$-values of tetracycline were positively correlated with those of spiramycin. This correlation was stronger for the strains that were resistant to streptomycin. Thus, the correlation observed between penicillin and spiramycin might depend upon the relationship between the values for tetracycline and penicillin.

In order to examine the influence of tetracycline, the material was divided into three groups of strains with varying sensitivity to penicillin and streptomycin (I, II, III), and subdivided into ten groups with varying sensitivity to tetracycline. The $\mathrm{IC}_{50}$-values of the tetracycline groups ranged from $\mathrm{IC}_{50} \leqq 0 \cdot 1 \mu \mathrm{g} . / \mathrm{ml}$. to $2 \cdot 26 \mu \mathrm{g} . / \mathrm{ml}$. (Table I).
Group I 179 strains sensitive to both penicillin and streptomycin.

Group II 100 strains less sensitive to penicillin and sensitive to streptomycin.

Group III 132 strains less sensitive to penicillin and resistant to streptomycin. (Three strains that were sensitive to penicillin but resistant to streptomycin were included in this group).

Group I No correlation was found between the penicillin and spiramycin values, either within each level of sensitivity to tetracycline or between the averages, since the correlation coefficients were not significantly different from zero.* Table I shows that, with decreasing levels of sensitivity to tetracycline, the average $\log$. $\mathrm{IC}_{50}$-values for both spiramycin and penicillin were increasing (sensitivity decreasing).

Group II A weak (but statistically significant) positive correlation was seen between the log. $\mathrm{IC}_{50}$-values of spiramycin and penicillin. The degree of correlation was only slightly reduced after subdivision according to tetracycline. The correlation coefficients before and after subdivision were 0.49 and 0.42 respectively. With decreasing sensitivity to tetracycline, the sensitivity to both spiramycin and penicillin was also decreasing.

*The "within" correlation coefficient was calculated as an average of the correlation coefficients for the different levels of tetracycline.

TABLE I

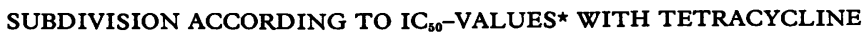
411 GONOCOCCAL STRAINS

\begin{tabular}{|c|c|c|c|c|c|c|c|c|c|c|}
\hline \multicolumn{2}{|c|}{ Group } & \multicolumn{3}{|c|}{$\begin{array}{l}\text { I } \\
\text { Strains sensitive to penicillin } \\
\text { and streptomycin }\end{array}$} & \multicolumn{3}{|c|}{$\begin{array}{l}\text { II } \\
\text { Strains less sensitive to penicillin } \\
\text { and sensitive to streptomycin }\end{array}$} & \multicolumn{3}{|c|}{$\begin{array}{l}\text { III } \\
\text { Strains less sensitive to penicillin } \\
\text { and resistant to streptomycin } \star \star\end{array}$} \\
\hline \multicolumn{2}{|c|}{ Tetracycline } & \multirow{2}{*}{ Number } & \multicolumn{2}{|c|}{ Mean of log. $\mathrm{IC}_{50}$-values } & \multirow{2}{*}{ Number } & \multicolumn{2}{|c|}{ Mean of log. $\mathrm{IC}_{50}-$ values } & \multirow{2}{*}{ Number } & \multicolumn{2}{|c|}{ Mean of log. $\mathrm{IC}_{50}-$ values } \\
\hline Group & $\mathrm{IC}_{50}-$ values & & Spiramycin & Penicillin & & Spiramycin & Penicillin & & Spiramycin & Penicillin \\
\hline $\begin{array}{r}1 \\
2 \\
3 \\
4 \\
5 \\
6 \\
7 \\
8 \\
9 \\
10\end{array}$ & $\begin{array}{c}\leqq 0 \cdot 10 \\
0.14 \\
0 \cdot 20 \\
0 \cdot 28 \\
0.40 \\
0.57 \\
0.80 \\
1.13 \\
1.60 \\
2 \cdot 26\end{array}$ & $\begin{array}{l}20 \\
44 \\
56 \\
46 \\
13\end{array}$ & $\begin{array}{l}-0.616 \\
-0.564 \\
-0.518 \\
-0.503 \\
-0.451\end{array}$ & $\begin{array}{l}-2.229 \\
-2.108 \\
-2.078 \\
-1.988 \\
-1.958\end{array}$ & $\begin{array}{r}1 \\
3 \\
3 \\
32 \\
33 \\
2 \\
6 \\
7 \\
12 \\
1\end{array}$ & $\begin{array}{r}-1.301 \\
-0.624 \\
-0.323 \\
-0.360 \\
-0.300 \\
0.016 \\
-0.150 \\
-0.323 \\
-0.120 \\
0.355\end{array}$ & $\begin{array}{l}-1.115 \\
-0.859 \\
-0.709 \\
-0.814 \\
-0.648 \\
-0.588 \\
-0.769 \\
-0.558 \\
-0.272 \\
-0.362\end{array}$ & $\begin{array}{r}3 \\
4 \\
12 \\
11 \\
3 \\
11 \\
23 \\
60 \\
5\end{array}$ & $\begin{array}{r}-0.774 \\
-0.925 \\
-0.488 \\
-0.421 \\
-0.676 \\
-0.458 \\
-0.105 \\
0.069 \\
0.339\end{array}$ & $\begin{array}{l}-1.160 \\
-1.642 \\
-0.724 \\
-0.573 \\
-0.859 \\
-0.663 \\
-0.287 \\
-0.167 \\
-0.031\end{array}$ \\
\hline \multicolumn{2}{|c|}{$\begin{array}{l}\text { Total } \\
\text { Standard deviation }\end{array}$} & 179 & $\begin{array}{r}-0.533 \\
0.278\end{array}$ & $\begin{array}{r}-2 \cdot 048 \\
0 \cdot 248\end{array}$ & 100 & $\begin{array}{r}-0.300 \\
0.263\end{array}$ & $\begin{array}{r}-0.663 \\
0.286\end{array}$ & $\begin{array}{c}132 \\
(129+3)\end{array}$ & $\begin{array}{r}-0.150 \\
0.331\end{array}$ & $\begin{array}{r}-0.393 \\
0.316\end{array}$ \\
\hline
\end{tabular}

$\star I C_{50}=50$ per cent. inhibitory concentration $\mu \mathrm{g} . / \mathrm{ml}$.

$\star \star T h r e e$ strains were sensitive to penicillin but resistant to streptomycin. 
Group III The spiramycin and penicillin values were positively correlated, and the correlation was stronger than that observed in Group II, the correlation coefficients being 0.77 and 0.49 respectively. The reduction in the correlation cofficients after subdivision according to tetracycline was also greater than in Group II (from 0.77 to 0.57 as against from 0.49 to 0.42 ). With decreasing sensitivity to tetracycline, the sensitivity to both spiramycin and penicillin was also decreasing. In Group III, the average log. $\mathrm{IC}_{50}$-values for spiramycin were lower than the corresponding * average $\log$. $\mathrm{IC}_{50}$-values for spiramycin in Group II. This means that the subdivision according to tetracycline does not remove the interdependence of spiramycin and streptomycin.

The sensitivity to erythromycin was determined for 93 gonococcal strains. In Fig. 1 the $\mathrm{IC}_{50^{-}}$ values of spiramycin are plotted on the abscissa and the corresponding zone diameters (in $\mathrm{mm}$.) obtained with erythromycin discs on the ordinate. The two sets of values are so closely correlated that they could be measuring the same substance.

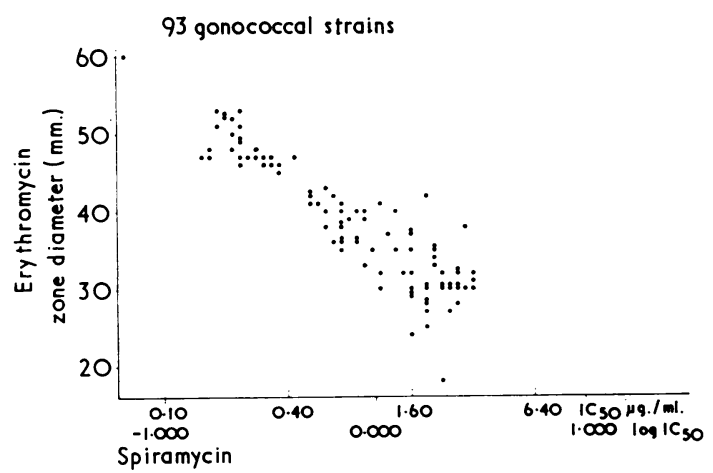

FIG. 1.-Comparison between erythromycin (zone diameter in $\mathrm{mm}$.) and spiramycin ( $\mathrm{IC}_{50}-$ values in $\mu \mathrm{g} . / \mathrm{ml}$.)

In Fig. 2 the $\mathrm{IC}_{50}$-values of penicillin are plotted against the zone diameters obtained with erythromycin. In this case also a positive correlation is demonstrated, but only for the strains that are less sensitive to penicillin, and the degree of correlation is weaker.

The present series of gonococcal strains comprises 44 strains with moderately decreased sensitivity to penicillin and either sensitivity (28) or resistance (16) to streptomycin. Such strains were rarely found in the previous series, and an astonishingly high number of strains at that level of sensitivity to penicillin were very sensitive to spiramycin and resistant to streptomycin. The distribution

$\star_{i . e .}$ within each level of sensitivity to tetracycline.

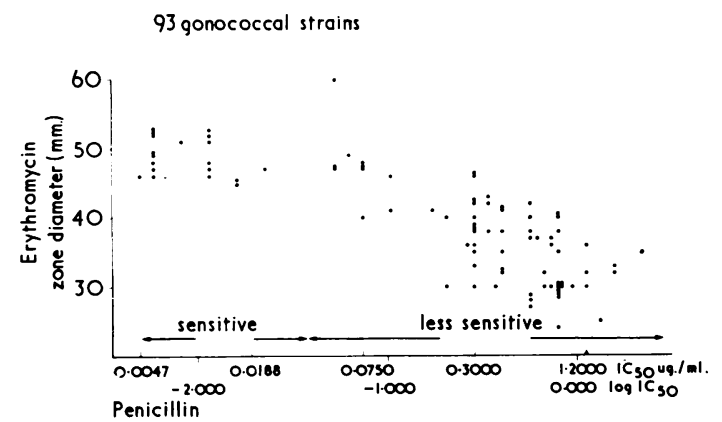

FIG. 2.-Comparison between erythromycin (zone diameters in $\mathrm{mm}$.) and penicillin ( $\mathrm{IC}_{50}-$ values in $\mu \mathrm{g} . / \mathrm{ml}$.)

of the 44 strains with respect to the sensitivity to spiramycin and streptomycin is shown in Table II.

TABLE II

RELATIONSHIP BETWEEN THE SENSITIVITY TO RELATIONSHIP BETSEET CORAMY SIN ANS MODERATELY SENSITIVE TO PENICILLIN (IC 50 -VALUES FROM 0.053 TO $0.25 \mu \mathrm{g} . / \mathrm{ml}$.)

\begin{tabular}{|c|c|c|c|c|c|}
\hline \multirow{3}{*}{ Spiramycin } & \multicolumn{5}{|c|}{ Streptomycin } \\
\hline & \multicolumn{2}{|c|}{ Sensitive } & \multicolumn{2}{|c|}{ Resistant } & \multirow{2}{*}{ Total } \\
\hline & No. & $\begin{array}{c}\text { Per } \\
\text { cent. }\end{array}$ & No. & $\begin{array}{c}\text { Per } \\
\text { cent. }\end{array}$ & \\
\hline $\mathrm{IC}_{50} \leqq 0.17 \mu \mathrm{g} . / \mathrm{ml}$ & 7 & 25 & 11 & 69 & 18 \\
\hline $\mathrm{IC}_{50} \geqq 0.20 \mu \mathrm{g} . / \mathrm{ml}$ & 21 & 75 & 5 & 31 & 26 \\
\hline Total & 28 & 100 & 16 & 100 & 44 \\
\hline
\end{tabular}

Only seven out of 28 strains (25 per cent.) sensitive to streptomycin are also sensitive to spiramycin $\left(\mathrm{IC}_{50} \leqq 0.17 \mu \mathrm{g} . / \mathrm{ml}\right.$.; arbitrary limit), whereas as many as eleven out of sixteen strains ( 69 per cent.) resistant to streptomycin are sensitive to spiramycin. This difference is statistically significant $(P=0.9$ per cent.).

Table III shows the results of the special experiment with five strains artificially made more resistant to penicillin. For purposes of comparison some previous results are included (Reyn and Bentzon, 1968). With increased resistance to penicillin, the resistance to both spiramycin and erythromycin is significantly increased, but the changes are less pronounced.

\section{Summary and Conclusions}

Irrespective of the response to streptomycin of 232 gonococcal strains less sensitive to penicillin, the positive relationship previously observed between the susceptibility to penicillin and spiramycin in vitro was confirmed. However, the correlation between penicillin and spiramycin was weaker for those strains that were sensitive to streptomycin. It was also confirmed that gonococcal 
TABLE III

MEAN RATIOS BETWEEN IC I $_{50}$-VALUES OF FIVE GONOCOCCAL STRAINS BEFORE AND AFTER SUBCULTURING ON MEDIUM WITH SODIUM PENICILLIN G ADDED

\begin{tabular}{|c|c|c|c|}
\hline & & \multicolumn{2}{|c|}{ Ratios of $\mathrm{IC}_{50}$-values ${ }^{\star}$} \\
\hline \multicolumn{2}{|c|}{ Antibiotic } & Pen. res. I: & Pen res. II: \\
\hline Penicillin & $\begin{array}{l}\text { Previous } \\
\text { Present }\end{array}$ & $\begin{array}{l}3 \cdot 4 \\
4 \cdot 0\end{array}$ & $\begin{array}{l}6 \cdot 7 \\
6 \cdot 4\end{array}$ \\
\hline Spiramycin & $\begin{array}{l}\text { Previous } \\
\text { Present }\end{array}$ & $\begin{array}{l}2 \cdot 0 \\
1 \cdot 7\end{array}$ & $\begin{array}{l}2 \cdot 2 \\
1 \cdot 8\end{array}$ \\
\hline Erythromycin & Present & 1.6 & $1 \cdot 8$ \\
\hline
\end{tabular}

Pen. res. orig. $=$ Mean of original $\mathrm{IC}_{50}-$ values for five strains.

Pen. res. I = Mean of $I_{50}$-values for the same five strain after 2 months' subculturing on medium with

Pen. res. II = Mean of $I_{50}$-values for the same five strains after 3 months' subculturing on medium with sodium penicillin $G$ added.

*The 95 per cent. limits of error are from 73 to 137 per cent. of the ratios.

strains with moderately decreased susceptibility to penicillin and resistance to streptomycin were especially sensitive to spiramycin (Reyn and Bentzon, 1968). As the $\mathrm{IC}_{50}$-values of tetracycline had been shown earlier to be correlated with both the penicillin and streptomycin values, the correlation between penicillin and spiramycin might depend upon the relationship to tetracycline. However, after subdivision of the material according to sensitivity to tetracycline, it was still possible to demonstrate a positive correlation between the average $\mathrm{IC}_{50}$-values of penicillin and spiramycin. The correlation was most pronounced for strains that were less sensitive to penicillin and also resistant to streptomycin.

The sensitivity to erythromycin was determined for 93 strains. Of these, 87 were isolated at various laboratories in the East Asian region in 1961 and 1967-1968. All the strains from the year 1961 were fully sensitive to erythromycin, but 33 of the 43 strains from the years 1967-1968 were only moderately sensitive and one was resistant to erythromycin (Reyn, 1969). The size of the zone diameters obtained with erythromycin was found to be so closely correlated with the $\mathrm{IC}_{50}$ - values obtained with spiramycin that the two methods might be measuring the same substance. This result is in agreement with the fact that spiramycin belongs to the macrolide group of antibiotics together with inter alia erythromycin (Abraham, 1965). For strains less sensitive to penicillin, the erythromycin results were also positively correlated with the penicillin results, but the correlation was weaker than that observed between spiramycin and erythromycin.
During recent years several antibiotics belonging to the macrolide group have been used in the therapy of gonorrhoea. Thus, the present and previous correlation observed between the $\mathrm{IC}_{50} 0^{-}$ values of spiramycin and penicillin may be a result of treating gonorrhoea with spiramycin, erythromycin, or oleandomycin. Cross-resistance ketween erythromycin and spiramycin has been reported previously for Staphylococcus aureus (Sutherland, 1962; Nakazawa, and Yamagishi, 1963; Russo, Carrozzo, DeVanna, and Pipitone, 1966).

However, the fact that gonococcal strains with artificially decreased sensitivity to penicillin also became a little, but statistically significantly, less sensitive to spiramycin and erythromycin remains unexplained (Reyn and Bentzon, 1968). Recently, Roiron and Durel* have found that strains made highly resistant to spiramycin simultaneously became resistant to other macrolides and to penicillin.

\section{REFERENCES}

Abraham, E. P. (1965). Amer. F. Med., 39, 692.

Durel, P., RoIron, V., and Nicod, G. (1967). Path. et Biol., 15, 1197.

Nakazawa, S., and Yamagishi, Y. (1963). Chemotherapy (fap.), 11, 61.

ReYN, A. (1961). Brit. f. vener. Dis., 37, 145.

- (1963). Acta derm.-venereol. (Stockh.), 43, 380.

(1959). Bull. Wld Hlth Org., 40, 257.

and Bentzon, M. W. (1968). Brit. F. vener. Dis., 44, 140 .

-, and Ericsson, H. (1963). Acta. path. microbiol. scand., 57, 235.

—, Korner, B., and Bentzon, M. W. (1958). Brit. F. vener. Dis., 34, 227.

Russo, R., Carrozzo, M., deVanna, F., and Pipitone, V. (1966). Boll. Ist. Sieroter. milan., 45, 452.

Schmidt, H., and LaRSEN, S. O. (1962). Acta derm.venereol. (Stockh.), 42, 294.

-, Niordson, A.-M., ReYN, A., and Bentzon, M. W. (1965). Brit. F. vener. Dis., 41, 120.

Sutherland, R. (1962). Brit. F. Pharmacol., 19, 99.

THomsen, V. F. (1962). Acta path. microbiol. scand., 54, 107.

Relations entre la sensibilité in vitro de Neisseria gonorrhoeae à la spiramycine, la pénicilline, la streptomycine, la tétracycline et l'érythromycine

\section{RÉSUMÉ}

Indépendamment de la réponse à la streptomycine de 232 souches de gonocoques moins sensibles à la pénicilline, la nette relation déjà observée-entre la sensibilité à la pénicilline et à la spiramycine in vitro fut confirmée. Cependant, la corrélation entre pénicilline et spiramycine

^Personal communication from Roiron and Durel (1968). 
fut plus faible pour celles des souches qui étaient sensibles à la streptomycine. Il a été également confirmé que les souches de gonocoques de sensibilité un peu diminuée à la pénicilline et résistantes à la streptomycine étaient spécialement sensibles à la spiramycine (Reyn et Bentzon, 1968). Comme il avait été démontré antérieurement que la concentration inhibitrice 50 pour cent, mesurée en $\mu \mathrm{g} . / \mathrm{ml}$. (valeur $\mathrm{IC}_{50}$ ), à la tétracycline était en relation avec les valeurs et de la pénicilline et de la streptomycine, il pouvait être possible que la corrélation entre pénicilline et spiramycine dépende de la relation avec la tétracycline. Cependant, en classant les souches selon leur sensibilité à la tétracycline, il restait possible de mettre en évidence une nette corrélation entre les valeurs $\mathrm{IC}_{50}$ moyennes vis-à-vis de pénicilline et de spiramycine. Cette corrélation fut moins prononcée pour les souches qui étaient moins sensibles à la pénicilline et résistantes aussi à la streptomycine.

La sensibilité à l'erythromycine fut établie pour 93 souches. Parmi celle-ci, 87 avaient éte isolées dans divers laboratoires de l'Est asiatique en 1961 et en 1967-68. Toutes les souches de l'année 1961 étaient entièrement sensibles à l'érythromycine, mais 33 des 43 souches des années 1967-68 n'étaient que modérément sensibles et une était résistante à l'érythromycine. La grandeur des diamètre des zones obtenues avec l'érythromycine se trouva être en corrélation si étroite avec les valeurs $\mathrm{IC}_{50}$ obtenues pour la spiramycine que les deux méthodes mesurent peut être la même substance.
Ce résultat s'accorde avec le fait que la spiramycine est un antibiotique du groupe des macrolides, comme l'est, entre autres, l'érythromycine (Abraham, 1965). Pour les souches moins sensibles à la pénicilline, les résultats pour l'érythromycine étaient aussi en nette corrélation avec les résultats pour la pénicilline, mais la corrélation était plus faible que celle observée entre spiramycine et érythromycine.

$\mathrm{Au}$ cours de ces dernières années, plusieurs antibiotiques du groupe des macrolides ont été employés dans le traitement de la gonococcie. Ainsi, la corrélation observée, actuellement et antérieurement, entre ces valeurs $\mathrm{IC}_{50}$ pour la spiramycine et la pénicilline peuvent être l'effet de traitements de la gonococcie par spiramycine, érythromycine ou oléandomycine. La résistance croisée entre érythromycine et spiramycine a été reportée antérieurement pour Staphylococcus aureus (Sutherland, 1962; Nakazawa et Yamagishi, 1963; Russo, Carozzo, de Vanna, et Pipitone, 1966).

Cependant, le fait que des souches de gonocoques dont la diminution de sensibilité à la pénicilline a été artificiellement produite sont aussi devenues légèrement-mais ceci est statistiquement significatif-moins sensibles à la spiramycine et à l'érythromycine demeure inexpliqué (Reyn et Bentzon, 1968). Récemment, Roiron et Durel ont trouvé que des souches rendues hautement résistantes à la spiramycine deviennent en même temps résistantes aux autres macrolides et à la pénicilline. 